\title{
Effect of High-Protein Breakfast Meals on Within-Day Appetite and Food Intake in Healthy Men and Women
}

\author{
William Buosi' ${ }^{1}$, David M. Bremner' ${ }^{1}$, Graham W. Horgan², Claire L. Fyfe' ${ }^{1}$, \\ Alexandra M. Johnstone ${ }^{1}$ \\ ${ }^{1}$ Rowett Institute of Nutrition and Health, University of Aberdeen, Aberdeen, UK \\ ${ }^{2}$ Biomathematics and Statistics Scotland, Aberdeen, UK \\ Email: alex.johnstone@abdn.ac.uk
}

Received 24 February 2015; accepted 14 March 2015; published 17 March 2015

Copyright @ 2015 by authors and Scientific Research Publishing Inc.

This work is licensed under the Creative Commons Attribution International License (CC BY). http://creativecommons.org/licenses/by/4.0/

c) (i) Open Access

\begin{abstract}
Breakfast is considered an important meal for daily appetite control. We examined the effect of high-protein breakfasts on within-day appetite sensations and subsequent ad libitum intake, in men and women. Twenty subjects attended on 4 occasions, to consume in a randomised order high-protein (30\% energy) breakfast meals, as, 1) maintenance (MTD) fed to energy requirements (2.67 MJ), 2) a weight-loss (WL) bacon-based meal breakfast (WL-B, 2.13 MJ), 3) a WL-chicken salad (WL-CS, 2.13 MJ) and 4) a WL-smoothie (WL-S, 2.08 MJ). The 3 HP-WL breakfasts elicited differences in hunger $(p=0.007)$, fullness $(p=0.029)$, desire to eat $(p=0.006)$ and prospective consumption $(p=0.020)$. The WL-B meal reduced hunger $(p=0.002)$ and enhanced fullness $(p=0.02)$, compared with the two other WL breakfasts. Although these differences were not reflected in ad libitum energy intake later in the day, a HP breakfast can modify morning satiety, which is important during dieting.
\end{abstract}

\section{Keywords}

Protein, Appetite, Weight Loss, Breakfast Meals, Lunch Intake

\section{Introduction}

The effects of breakfast presentation (type and composition) on appetite remain unclear. Regular breakfasts are recommended as a strategy to help individuals achieve and maintain a healthy body weight [1]. Missing breakfast causes hormonal and metabolic, and compensatory changes in appetite later in the day [2]. Nutrient compo- 
sition of the breakfast may also impact total daily energy intake. Dietary protein is the most satiating macronutrient, an effect amplified during dieting [3]. Moreover, it has been suggested that protein is more satiating at breakfast than at other meal times [4].

However, most short-term (within-day) studies have used covert diet manipulation (e.g. liquid dairy based pre-load) whereby the ingredients are hidden to participants [2], so that pre-ingestion cues do not influence satiety. A number of studies have covertly studied the effect of different types of proteins on satiety [5]. Fewer data compare sources of breakfast protein fed as recognisable, individual food items [6], as meals [7], or even as snacks [8]. Therefore it is unclear whether combination of different types of protein, fed as meals, can influence subjective motivation to eat at breakfast time and ad libitum food intake later in the day during dieting. The purpose of this study was therefore to compare the effects of consuming high-protein weight loss (WL) meals on appetite responses, in men and women.

\section{Participants and Methods}

Twenty non-smoking healthy subjects (15 female and 5 male) were recruited from poster advertisement. All vo-

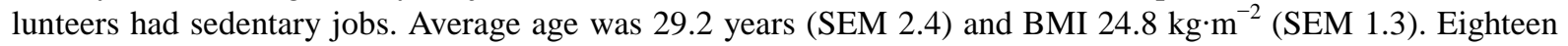
volunteers who consumed a breakfast meal before 9 am on weekdays and before noon at weekends, were classified as habitual breakfast eaters. All subjects gave written informed consent, reviewed by the Rowett Ethics Committee. The test meals contained, $30 \%$ protein, $40 \%$ carbohydrate and $30 \%$ fat as energy, as 1) maintenance meal (MTD, $2.67 \mathrm{MJ}$ ), fed to energy requirements containing cereal with milk, toast with jam, ham and scrambled eggs 2) WL-B bacon breakfast (2.13 MJ, containing cereal with milk, a warm bacon and cheese toasted sandwich and grilled tomatoes), 3) WL-C (chicken salad, 2.13 MJ) and 4) WL-S as a fruit dairy smoothie (2.08 $\mathrm{MJ})$. The subjects' energy requirements (ER) were estimated as $1.3 \times$ measured resting metabolic rate [9] (RMR), using a ventilated hood. The MTD and WL meals were fed to 30\% ER and 30\% RMR, respectively. Volunteers recorded subjective motivation to eat and meal pleasantness using half-hourly visual analogue scales (VAS) as described previously [10]. Volunteers were then asked to stay within the research centre and were instructed to keep a low level of physical activity. The fact that all breakfasts were high in protein and fed to WL or maintenance requirements was hidden from the volunteers. Participants were made aware that two hours after breakfast, they could snack from a buffet. This was a selection of sweet and savoury, high-calorie and low-calorie 26 readyto-eat foods including crisps, yoghurt, cheese, biscuits, sandwiches, fruit, ready meals, soup and vegetables, which were stored in a designated individual refrigerator. The investigator met volunteers in the Human Nutrition Unit dining room 5 hours after breakfast for lunch presenting them again with the lunch selection, ensuring the volunteers could locate all the items that were on offer or could get more items if required. An analysis of variance (ANOVA) was carried out with terms for volunteer, day order and breakfast type, using Genstat 13.2 (VSN International Limited).

\section{Results}

\subsection{Appetite Response (Figure 1(a) and Figure 1(b))}

There was a difference between the 3 HPWL breakfasts in hunger $(p=0.007)$, fullness $(p=0.029)$, desire to eat $(p=0.006)$ and prospective consumption $(p=0.020)$. The HPWL-bacon breakfast reduced hunger $(p=0.002)$, and enhanced fullness ( $p=0.02$ ) (Figure 1(a) and Figure 1(b)) compared to the other two WL breakfasts. Indeed, both hunger and fullness on the WL-B diet were similar to that for the higher energy containing maintenance breakfast (MTD). Subjects did not seem to perceive the caloric restriction when consuming the HPWLbacon breakfast. Compared with the maintenance meal (MTD) subjects were more hungry $(p=0.001)$ and less full $(p=0.003)$ after the WL-Smoothie and WL-CS breakfasts. Post-meal ratings reported similar pleasantness $(p=0.379)$ for all meals.

\subsection{Ad libitum Food Intake (Table 1)}

All the foods and drinks that were consumed between 2 and 5 hours, or between 5 and 6 hours after breakfast were classified, respectively, as snack or lunch intake. Despite differences in motivation to eat, subjects did not change ad libitum combined snack and lunch energy intake ( $p=0.922)$ (Table 1$)$. Subjects did consume less snack energy intake after MTD breakfast $(p=0.032)$, in comparison to the WL breakfasts, but total energy in- 


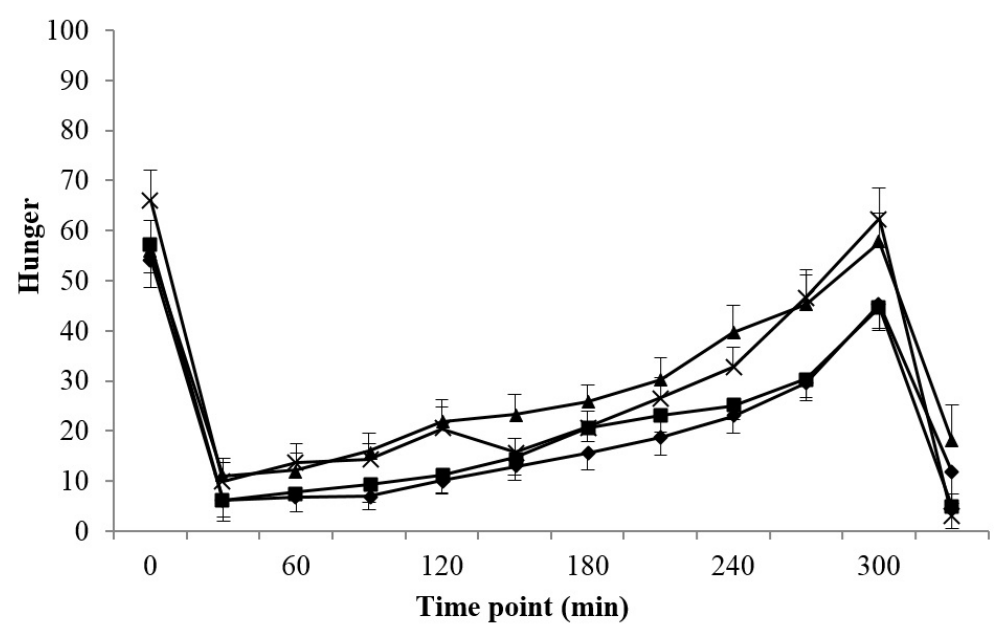

(a)

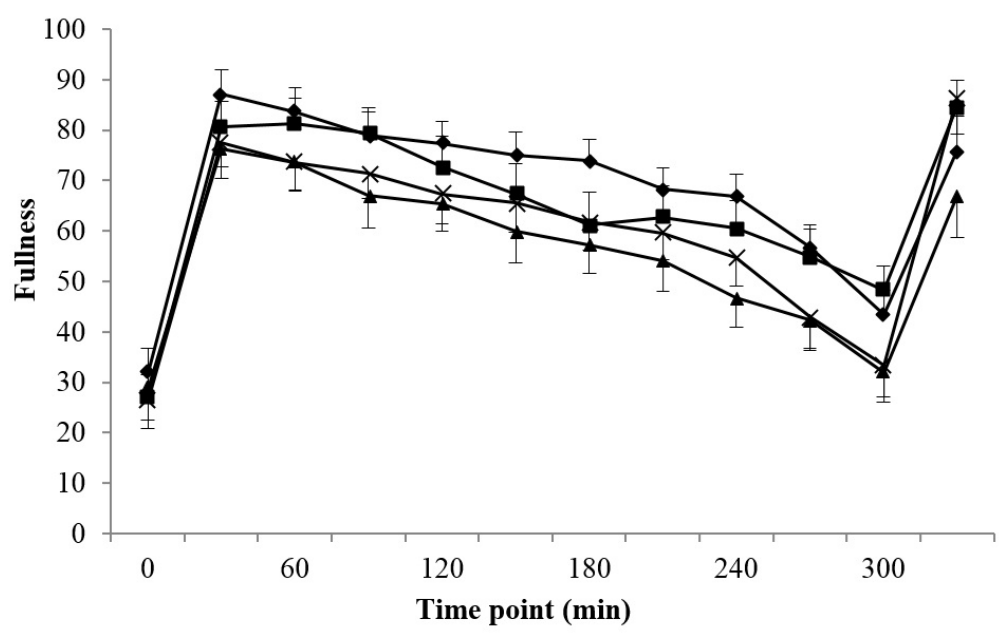

(b)

Figure 1. (a) Plot of mean ( $\pm \mathrm{SEM})$ hunger $(\mathrm{mm})$, as assessed with Visual Analogue Scales after consumption of a maintenance breakfast (BF) $(\diamond)$, a weightloss (WL) cooked breakfast (ם), a WL chicken salad BF ( $\boldsymbol{\Delta})$ and a WL smoothie $\mathrm{BF}(\times)$; (b) Plot of mean $( \pm \mathrm{SEM})$ fullness $(\mathrm{mm})$, as assessed with Visual Analogue Scales after consumption of a maintenance breakfast (BF) $(\downarrow)$, a weightloss (WL) cooked breakfast $(\boldsymbol{\square})$, a WL chicken salad BF $(\boldsymbol{\Delta})$ and a WL smoothie $\mathrm{BF}(\times)$.

take (breakfast, lunch and snack combined) across the morning did not change significantly $(p=0.285)$.

\section{Discussion}

We investigated the effects of different sources of high-protein WL breakfasts provided as recognisable meals, on subjective appetite and energy intake and compared the response to a maintenance diet. The WL-bacon breakfast enhanced fullness and reduced hunger to a similar extent as the maintenance breakfast, compared to the WL-chicken salad and the WL-smoothie meals. Many studies that investigated appetite responses to food manipulation use the test meal paradigm, providing preloads to participants. In the present study, familiar food items were provided and the size of the breakfast was individualized with respect to energy requirements, based on metabolic rate. The warm cooked breakfast meal based on meat protein was more satiating than the dairy or chicken rich sources, despite similar nutrient profile. Dietary proteins from different sources have been shown to influence satiety [6]. They found that fish was more satiating than the other sources of proteins which included 
Table 1. Mean intakes at the fixed breakfasts, ad libitum snacks, lunch, and total (in MJ) after weight loss and maintenance high-protein breakfasts.

\begin{tabular}{|c|c|c|c|c|c|c|c|}
\hline \multirow{3}{*}{ Meal } & \multicolumn{4}{|c|}{ Intervention breakfasts } & \multirow{3}{*}{ SEM } & \multirow{3}{*}{$p$} & \multirow{3}{*}{$p^{*}$} \\
\hline & \multicolumn{3}{|c|}{ Weight-loss } & \multirow{2}{*}{ MTD } & & & \\
\hline & WL-B & WL-CS & WL-S & & & & \\
\hline Breakfast & 2.13 & 2.13 & 2.08 & 2.67 & 0.049 & $<0.001$ & 0.505 \\
\hline Snack and lunch intake & 4.04 & 4.16 & 4.04 & 3.97 & 0.279 & 0.922 & 0.885 \\
\hline Of which snacks & 0.61 & 0.62 & 0.60 & 0.34 & & $0.032^{a}$ & 0.626 \\
\hline Total morning intake & 6.17 & 6.29 & 6.12 & 6.64 & 0.289 & 0.285 & 0.837 \\
\hline
\end{tabular}

${ }^{a} p$-value for snack was calculated from the log values of the intakes as their distribution was skewed. $p^{*}$ is the $p$-value associated to the analysis of variance performed for the three weight-loss diets only.

beef and chicken. The acute effect of different liquid protein sources has been investigated [11], with the area under the curve for hunger lower for a whey meal than with the tuna, egg and meat meals. In our study, volunteers felt significantly less hungry after the cooked breakfast than after the dairy smoothie and the cold chicken salad meal. The literature indicates that amino acid composition, rate of absorption, and protein/food texture may be important factors for protein-induced-satiety [12]. On balance, evidence from studies where manipulations were covert suggests that amount of protein is more important than the type [7].

In addition to the metabolic responses to different nutrients, psychological factors can also influence both perception and physiological function. For example, food presentation is a useful parameter to influence appetite during weight loss. It has been previously reported that telling consumers about nutritional profile influences gut hormone release, even when the same food is actually served [13]. In our study, the warm cooked meal gave the greatest response in fullness, which was comparable to the maintenance breakfast. It may be that subjects perceive or expect [14] a cooked breakfast to be more satiating than a dairy and fruit smoothie or a cold chicken salad meal.

Liquid versus solid breakfast types may have an influence on appetite due to gastric rate of delivery and release of gut hormones in response. In adults, a study found that the satiating power of protein was stronger when consumed in a solid form with water than when consumed a liquid form [15]. Foods high in carbohydrate and high in fat also seem to be more satiating when ingested as a solid than as a liquid [16]. This has been suggested to be valid in adolescents where volunteers reported lower appetite, as in our study, during two hours after a protein-rich solid breakfast compared to a liquid version [17].

It has been shown that breakfast consumers lost more weight when they did not eat breakfast, and conversely, those who regularly skipped breakfast lost more weight when they were made to eat a standard breakfast, which suggests that changing the usual eating pattern may have a greater effect than breakfast per se in those aiming to lose weight [18]. The effect of omitting breakfast in regular eaters as opposed to reintroducing breakfast to those who skip breakfast both report similar effects in regard to energy intake. In our study, volunteers were regular breakfast eaters and results may be different for those who do not habitually consume breakfast.

\section{Conclusion}

These findings provide insight into the effects of breakfast meals on appetite and suggest that further research is warranted. Breakfast meal type is an important choice influencing morning motivation to eat during weight loss.

\section{Acknowledgements}

The Rowett Institute and Biomathematics and Statistics Scotland are grateful to the Scottish Government for funding this work. We thank the Rowett Human Nutrition Unit staff for their technical help with the interventions. Staff members who helped include Jean Bryce, Nina Lamza and Karen Taylor.

The Rowett Institute and Biomathematics and Statistics Scotland are grateful to the Scottish Government for funding this work. 


\section{References}

[1] Astbury, N.M., Taylor, M.A. and Macdonald, I.A. (2011) Breakfast Consumption Affects Appetite, Energy Intake, and the Metabolic and Endocrine Responses to Foods Consumed Later in the Day in Male Habitual Breakfast Eaters. Journal of Nutrition, 141, 1381-1389. http://dx.doi.org/10.3945/jn.110.128645

[2] Bendtsen, L.Q., Lorenzen, J.K., Bendsen, N., Rasmussen, C. and Astrup, A. (2013) Effect of Dairy Proteins on Appetite, Energy Expenditure, Body Weight, and Composition: A Review of the Evidence from Controlled Clinical Trials. Advances in Nutrition, 4, 418-438. http://dx.doi.org/10.3945/an.113.003723

[3] Astrup, A. (2005) The Satiating Power of Protein-A Key to Obesity Prevention? American Journal of Clinical Nutrition, 82, 1-2.

[4] Leidy, H.J., Bossingham, M.J., Mattes, R.D. and Campbell, W.W. (2009) Increased Dietary Protein Consumed at Breakfast Leads to an Initial and Sustained Feeling of Fullness during Energy Restriction Compared to Other Meal Times. British Journal of Nutrition, 101, 798-803. http://dx.doi.org/10.1017/S0007114508051532

[5] Veldhorst, M.A.B., Nieuwenhuizen, A.G., Hochstenbach-Waelen, A., et al. (2009) Comparison of the Effects of a Highand Normal-Casein Breakfast on Satiety, "Satiety” Hormones, Plasma Amino Acids and Subsequent Energy Intake. British Journal of Nutrition, 101, 295-303. http://dx.doi.org/10.1017/S0007114508003061

[6] Uhe, A.M., Collier, G.R. and O’Dea, K. (1992) A Comparison of the Effects of Beef, Chicken and Fish Protein on Satiety and Amino Acid Profiles in Lean Male Subjects. Journal of Nutrition, 122, 467-472.

[7] Lang, V., Bellisle, F., Oppert, J., et al. (1998) Satiating Effect of Proteins in Healthy Subjects: A Comparison of Egg Albumin, Casein, Gelatin, Soy Protein, Pea Protein, and Wheat Gluten. American Journal of Clinical Nutrition, 67, 11971204.

[8] Dougkas, A., Minihane, A.M., Givens, D.I., Reynolds, C.K. and Yaqoob, P. (2012) Differential Effects of Dairy Snacks on Appetite, but Not Overall Energy Intake. British Journal of Nutrition, 108, 2274-2285. http://dx.doi.org/10.1017/S0007114512000323

[9] National Research Council (1989) Energy. In: Recommended Dietary Allowances, 10th Edition, National Academies Press, Washington DC, 24-38.

[10] Flint, A., Raben, A., Blundell, J.E. and Astrup, A. (2000) Reproducibility, Power and Validity of Visual Analogue Scales in Assessment of Appetite Sensations in Single Test Meal Studies. International Journal of Obesity, 24, 38-48. http://dx.doi.org/10.1038/sj.ijo.0801083

[11] Pal, S. and Ellis, V. (2010) The Acute Effects of Four Protein Meals on Insulin, Glucose, Appetite and Energy Intake in Lean Men. British Journal of Nutrition, 104, 1241-1248. http://dx.doi.org/10.1017/S0007114510001911

[12] Anderson, G.H., Tecimer, S.N., Shah, D. and Zafar, T.A. (2004) Protein Source, Quantity, and Time of Consumption Determine the Effect of Proteins on Short-Term Food Intake in Young Men. Journal of Nutrition, 134, 3011-3015.

[13] Crum, A.J., Corbin, W.R., Brownell, K.D. and Salovey, P. (2011) Mind over Milkshakes: Mindsets, Not Just Nutrients, Determine Ghrelin Response. Health Psychology, 30, 424-429. http://dx.doi.org/10.1037/a0023467

[14] Brunstrom, J.M., Brown, S., Hinton, E.C., Rogers, P.J. and Fay, S.H. (2011) “Expected Satiety” Changes Hunger and Fullness in the Inter-Meal Interval. Appetite, 56, 310-315. http://dx.doi.org/10.1016/j.appet.2011.01.002

[15] Martens, M.J.I. and Westerterp-Plantenga, M.S. (2012) Mode of Consumption Plays a Role in Alleviating Hunger and Thirst. Obesity, 20, 517-524. http://dx.doi.org/10.1038/oby.2011.345

[16] Mourao, D.M., Bressan, J., Campbell, W.W. and Mattes, R.D. (2011) Effects of Food Form on Appetite and Energy Intake in Lean and Obese Young Adults. International Journal of Obesity, 31, 1688-1695. http://dx.doi.org/10.1038/sj.ijo.0803667

[17] Leidy, H.J., Bales-Voelker, L.I. and Harris, C.T. (2011) A Protein-Rich Beverage Consumed as a Breakfast Meal Leads to Weaker Appetitive and Dietary Responses v. a Protein-Rich Solid Breakfast Meal in Adolescents. British Journal of Nutrition, 106, 37-41. http://dx.doi.org/10.1017/S0007114511000122

[18] Schlundt, D.G., Hill, J.O., Sbrocco, T., Pope-Cordle, J. and Sharp, T. (1992) The Role of Breakfast in the Treatment of Obesity: A Randomized Clinical Trial. American Journal of Clinical Nutrition, 55, 645-651. 